\title{
Covered Stent Placement for Duodenal Obstruction in Pancreatic Cancer
}

\author{
Hiromi Kasugai Yumi Asano Kenta Iguchi Takashi Uchiyama Hiroshi lida Hiroki Endo \\ Kunihiro Hosono Yasunari Sakamoto Koji Fujita Masato Yoneda Hirokazu Takahashi \\ Tomoko Koide Chikako Tokoro Ayumu Goto Yasunobu Abe Noritoshi Kobayashi \\ Kensuke Kubota Shin Maeda Atsushi Nakajima Masahiko Inamori \\ Gastroenterology Division, Yokohama City University Hospital, Yokohama, Japan
}

Dear Sir,

A 60-year-old man with pancreatic cancer was admitted to our hospital with vomiting. He had received a metallic stent placement for biliary stenosis 2 months prior to admittance. Upper endoscopy examination revealed that his duodenum showed stenosis with pancreatic cancer. Following balloon dilatation, duodenal covered stent placement was performed (fig. 1). After the procedure, the patient was able to eat ordinarily.
Patients with advanced pancreatic carcinoma often show stricture of the duodenum and food cannot pass through the duodenum. Duodenal stenting has become a popular treatment in cases of malignant stenosis. Duodenal stenting allows the patients to improve their quality of life.

In conclusion, we report the successful expansion of the obstructed duodenum by duodenal stent placement. We believe that this procedure should be offered as a treatment option for patients with stricture of the duodenum.

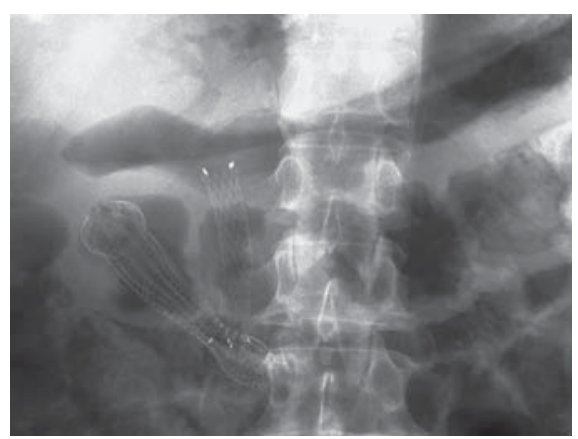

Fig. 1. Duodenal covered stent placement.

\section{KARGER}

Fax +41613061234 E-Mail karger@karger.ch www.karger.com www.karger.com/dig
M. Inamori, $\mathrm{MD}, \mathrm{PhD}$

Gastroenterology Division, Yokohama City University Hospital

3-9 Fukuura, Kanazawa-ku, Yokohama, 236-0004 Japan

Tel. +81 45787 2640, Fax +81 457843546

E-Mail inamorim@med.yokohama-cu.ac.jp 